\title{
Critical Discourse Analysis of Political Discourse A Case Study of Trump's TV Speech
}

\author{
Lirong Tian \\ School of Foreign Languages and Literatures, Chongqing Normal University, Chongqing, China
}

\begin{abstract}
Critical discourse analysis (CDA) is an effective method of the discourse analysis. It is aimed at analyzing the special relationship between power and the traditional ideology in implied discourse. Traditional discourse analysis always analyzes the structure and composition of discourse in terms of linguistic features, CDA makes language analysis more creative. It deeply explores the inherent potential of language and systematically interprets the deep meaning of discourse. This paper will take the specific corpus, namely Trump's TV speech, as the language material, Halliday's systematic functional grammar as the theoretical basis, and physicality, modality and personal pronoun as the framework. This paper studies how speakers in political speech use language to shorten the distance between people and win people's affirmation and support from the aspects of transitivity analysis, modality analysis and personal pronoun.
\end{abstract}

Index Terms - CDA, systemic-functional grammar, transitivity, modality, personal pronoun

\section{INTRODUCTION}

Political speech is "a kind of speech in which people state one's position, expound opinions and propaganda propositions in the state's internal affairs and external relations" (Li \& Zou, 2003, p.29). The researchers showed that "in order to build a good image of the party in the public and create favorable conditions for its future development in the political field, the speaker would skillfully use certain language skills and strategies" (Zhang, 2005). The concept of ideology (Geng, 2012) has been interpreted by Napoleon, Marx, Al jammed, Antonio Gramsci and many others since it was first proposed by The French philosopher Destutt de Tracy, but it has a new meaning in today's critical discourse analysis. It refers to a belief and value Shared and taken for granted by social groups (Ding \& Liao, 2011, p.101).

CDA studies the relationship between language, power and ideology, and expounds how discourse originates from and serves the social structure and power relations (Xin \& Gao , 2013). Discourse is a form of social practice in which language reflects power relations and reappears ideology in the social context (Tian, 2009, p.7). It has obvious ideological function. As an important political discourse, political speech is interwoven with power and power operation, so it is a focus of this kind of research. Taking the critical discourse theory as the framework, the critical discourse analysis method as the methodology, and the TV speech of US President Trump as an example, this paper will explore the deep meaning of transitivity, personal pronouns and modality in this political discourse.

\section{The TheORETICAL BASIS AND ReSEARCh MEthods OF CDA}

\section{A. Critical Discourse Analysis Theory}

CDA, also known as critical linguistics, began with the concept of "critical linguistics" proposed by Fowler et al. (1979) in the late 1970s. Fairclough (1989) began to pay attention to the phenomenon of social rights in discourse, which opened the prelude of critical discourse analysis. CDA believes that the essence of discourse is social practice, which is not only restricted by social practice, but also counter-productive. It can actively construct social practice and play a role in constructing social identity, social relations, knowledge and meaning system (Ji \& Xin, 2009). There is a close relationship between language and culture. Language is a basic and important part of a specific culture and has an essential and irreplaceable influence on culture (Hu, 2002, p.176). Language can indirectly affect users' thinking and behavior to some extent through a large amount of preset information. Such a conventional language system and its coded meaning system will lead to the "legalization" of ideology (Xin, 2005, p.39). Under the appearance of linguistic form, the subtle relationship between language, power and ideology is implied in the discourse, especially the popular discourse, and how the ruling class uses language to realize ideological control and maintain its dominant position. The core task of CDA is to expose the essence behind the linguistic representation, that is, to enhance people's language awareness, improve their ability to appreciate and criticize the use of language, and deal with the increasingly extensive intervention of language in modern life with a critical eye (Xin, 2002). Therefore, popular discourse and official discourse have become the main research objects of CDA. By exploring the deep ideological meaning of popular discourse, CDA reveals the intricate connections between discourse and social structure and social relations, as well as the bias and potential unequal power expressed by discourse in political discourse, and finally raises people's awareness of resisting the abuse, domination and inequality of social power. 


\section{B. Critical Discourse Analysis Methodology}

Halliday's systemic-functional linguistics is regarded as the most important analytical tool in critical discourse analysis, and the relationship between the two can be traced back to the 1970s. Halliday's systemic functional linguistics holds that people choose languages according to the social functions carried by language forms when they use them, which is quite consistent with the theoretical hypothesis of CDA. Therefore, CDA methodology is mainly based on systemic functional linguistics. Halliday believes that language has three meta-functions, namely, conceptual function, interpersonal function and discourse function. These three functions meet the three needs of language users, namely, describing the experience of the objective world, constructing social relations and confirming identity, and organizing discourse (Zeng, 2009). The function of concept is mainly reflected by transitive system. Interpersonal function is mainly reflected by mood structure and modal system, modal verbs, adjectives, adverbs, personal pronouns and substantive verbs can all express modal meanings (Xin, 2005).

\section{CORPuS ANALYSIS}

\section{A. Transitivity}

Transitivity is a semantic system whose function is to "enable people to see how the speaker expresses his or her inner world and his or her views of what is happening in the real world through transitivity". Transitivity mainly reflects the conceptual function of language, which expresses people's experience of the real world and the inner world in several processes. Halliday thought that the system of transitivity can divide human experience into six different processes: Material Process, Mental Process, Relational Process, Behavioral Process, Verbal Process, and Existential Process (Hu, 2008, p.75). Which process the speaker prefers to use is ideologically driven, which means that the emphasis in the presentation is different. The six processes are shown in Table 1:

TABLE 1

SiX PROCESSES OF A PHYSICAL SySTEM

\begin{tabular}{|c|c|c|c|c|c|c|}
\hline procedural type & $\begin{array}{c}\text { material } \\
\text { process }\end{array}$ & mental process & relational process & $\begin{array}{c}\text { verbal } \\
\text { processes }\end{array}$ & $\begin{array}{c}\text { behavioral } \\
\text { process }\end{array}$ & $\begin{array}{c}\text { existential } \\
\text { process }\end{array}$ \\
\hline core meaning & do, happen & sense, thought & $\begin{array}{l}\text { Attribution, } \\
\text { identification }\end{array}$ & talk & behavior & existence \\
\hline participant & $\begin{array}{c}\text { movement } \\
\text { goal }\end{array}$ & $\begin{array}{c}\text { feeler、 } \\
\text { phenomenon }\end{array}$ & $\begin{array}{c}\text { Carriers and } \\
\text { discriminators; } \\
\text { Symbol, value }\end{array}$ & $\begin{array}{l}\text { Speaker, } \\
\text { receiver, } \\
\text { utterance }\end{array}$ & & $\begin{array}{c}\text { the } \\
\text { existent }\end{array}$ \\
\hline
\end{tabular}

Material processes and relational processes more effectively express the reality of the objective world and the relationship between objective things, so they are favored by speakers. The President's speech has a specific political purpose, and the speaker usually uses material and relational processes to enhance the objectivity of his speech content and make it more convincing. There are a total of 116 sentences in the whole text, and each process appears, mainly material process and relational process, with the number of 86 and 30 respectively, accounting for $57.7 \%$ and $20.1 \%$ of the total clauses. According to statistics, the material process occupies a large proportion, but there are also related processes, the two are interlocked and arranged properly, each material process has to achieve the purpose of the speaker's speech. Through the summary and analysis of the article, it can be seen that the speaker mainly involved in the material process to enhance people's empathy, so as to win people's support and affirmation. For example, when he mentions the member of Congress who was wounded by a gunman, he is careful about his choice of words. He used some words such as "beloved, embody, dedicated, devoted, committed" to embody the spirit of him as a member of parliament, serving the people wholeheartedly and not fearing the sacrifice. Many positive words, such as fight for, pull for, pray for, pledge to him our full and total support, are also used in the description of the attitude of people towards the hero, which highlights that all Americans are encouraging, praying for and giving them fully enough support for the injured people and demonstrates flexibility in language selection.

Relational processes are the most direct means of evaluation or judgment in transitivity systems (Hodge \& Kress, 1979, p.113). Examples of typical relational processes in the discourse are selected below for analysis.

(1) what unites us is so much stronger: our love of country, our devotion to its people.

(2) Let us always remember that our job is to serve and represent the whole American People - and that we are all children of the same God.

(3) They will become brilliant technicians who revitalize American manufacturing.

They will become welders who forge from fire, amazing works of iron and steel and art.

And they will become entrepreneurs who revolutionize entire industries.

(4) Today, this is the message I want every young American to hear: there is dignity in every honest job, and there is nobility in every honest worker.

(1) Government defines the relationships that bind us together are the love of our country and the people. (2) A noun phrase defines the job of government is to serve and represent the People of the United States. We are all children of the same God. (3) It is a definition of the financial support and job information that this speech is intended to convey. They will become outstanding technicians, welders who will use fire to create outstanding works of steel and art, and 
entrepreneurs who will revolutionize industries. (4) Every job has dignity and every honest worker is noble. It expresses Trump's respect for working people. What he wants to build is a government of the people's sovereignty and full exercise of the power of the people.

\section{B. Modality}

A modal verb

The modality system expresses the interpersonal function, the speaker's judgment on the validity of his/her proposition in statements and questions, the obligation demanded of the other party in the command and the personal will expressed in the proposal (Zhang, 2005, p.192). Modality system is one of the important means to express interpersonal meaning by expressing the intermediate degree or state between positive and negative. Halliday believes that modality is often reflected through modal verbs, modal adverbs and a mixture of the two (Halliday, 1994, p.362). Modality reflects the speaker's judgment on the authenticity of his or her proposition, the enforceability of its requirements, and the willingness to be expressed in the proposal ( $\mathrm{Li} \&$ Zhong, 2002). Modal verbs are a way of expressing modal meaning. In this paper, we mainly study the use of modal verbs. There are 643 words in trump's speech, among which 11 are modal verbs, accounting for $1.7 \%$ of the total vocabulary. The usage of modal verbs is as follows:

TABLE 2

FREQUENCY OF MODAL VERBS USE

\begin{tabular}{|c|c|c|c|c|c|}
\hline modal verb & Will & must & can & need & should \\
\hline number & 9 & 1 & 0 & 1 & 0 \\
\hline frequency & $81.8 \%$ & $9.1 \%$ & $0 \%$ & $9.1 \%$ & $0 \%$ \\
\hline
\end{tabular}

The use of modal verbs in speeches plays an important role in the presentation of special meanings. Generally speaking, "can" and "will" are mainly used when talking about government preferences or achievable goals that voters in the United States can enjoy, while "should", "need" and "must" are often used to emphasize the position of the United States and what the country is doing for the people. The more obvious examples in the text are as follows:

(1) Under our plan, young Americans will have a pathway to exciting and fulfilling careers.

They will become brilliant technicians who revitalize American manufacturing.

They will become welders who forge from fire, amazing works of iron and steel and art.

And they will become entrepreneurs who revolutionize entire industries.

(2) Every day, as your President, I will be committed to this goal.

(3) Now more than ever, these values must guide us - and bring us closer together.

(4) On Thursday, I signed an Executive Order to launch a groundbreaking new Apprenticeship Initiative that help young Americans learn the skills they need to find a rewarding career, earn a great living, and support themselves and their families.

The statistical results show that the most frequently used modals in Trump's speech are medium-modal verbs, accounting for 81.8 percent of the total number of modals. The high frequent occurrence of medium-modal verbs indicates Trump's political philosophy and lays out a blueprint for future efforts. The modal verb Will was used nine times in this speech. The analysis of the context in which will is used shows that the prediction, on the one hand, expresses the difficult task ahead for the United States, and on the other hand, demonstrates the President's commitment to the people. Underscoring the Trump administration's commitment to economic opportunity for all. The use of Will reflects Trump's firm belief and determination, and continues the keynote of each speech, namely "Make America Great Again". The high-modal verb "must" appears once in the speech, expressing his subjective judgment and reflecting Trump's determination to unite with every American people as the President of the United States.

\section{Pronoun}

Interpersonal function means that in addition to conveying information, language also has the function of conveying the speaker's attitude towards the listener and expressing the speaker's identity, status, attitude and motivation. For example, how to address someone reflects the attitude of the author (speaker) (Zeng, 2009). Personal pronouns play an important role in connecting the speaker and the audience. Different pronouns can reflect the distance between the speaker and the audience and the speaker's emotion in speech. This paper focuses on the use of personal pronouns in the interpersonal function in Trump's speech.

TABLE 3

FREQUENCY OF PERSONAL PRONOUNS

\begin{tabular}{|l|c|c|c|c|c|}
\hline \multirow{2}{*}{$\begin{array}{l}\text { personal } \\
\text { pronoun }\end{array}$} & \multicolumn{2}{|c|}{ first person } & second person & \multicolumn{2}{c|}{ third person } \\
\cline { 2 - 6 } & $\mathrm{I} / \mathrm{me} / \mathrm{my}$ & we/us/our & you/your & he/she/him/her/his & they/them/their \\
\hline number & 9 & 26 & 3 & 12 & 16 \\
\hline frequency & \multicolumn{2}{|c|}{$53 \%$} & \multicolumn{2}{|c|}{$22.7 \%$} & $24.3 \%$ \\
\hline
\end{tabular}


Statistics show that the highest frequency of occurrence in this text is the first person, in which "we" appears 7 times, "US" 6 times and "our" 13 times, with a total of 35 times. "I, me my" 9 times; Third person also appeared more frequently, 28 times in total. The second person "you, your" 3 times. Trump rarely uses the singular "I, me, my", and use more "we, our, us," including the audience, create a friendly atmosphere, closer the distance of the President with ordinary people, let people share the same emotion, and form a potential of community and belonging. The use of "we/our/us" makes everyone seem as one, touches the emotions of the audience, and makes people feel that the future and direction of the United States is decided by all Americans, and that everyone should participate in the new initiatives centered on the new administration and the revitalization of the American economy.

It was worth noting that trump repeatedly used the first person pronouns "we, our" in his speech, like "our Nation, our support, our cities, our heart, our plan, our love, our focus, our Job". In addition to creating the mood and getting closer to voters, the words were used to express the theme of people's supremacy and American supremacy and unite all Americans under the banner of patriotism. Third person pronouns are also used a lot. They represent the younger generation of Americans and the hero Steve mentioned in the article. They also have a more profound connotation, conveying the belief that the state exists to serve the people. They represent the best, and we salute to them. It is the love of country and loyalty to the people that tight us together. This kind of power is extremely strong and can gather the people, maintaining trump's power system.

\section{CONCLUSIONS}

This paper interprets US President Trump's TV speech from the perspective of critical discourse analysis. The analysis results show that Trump used multiple language strategies in his speech to actively build the image of a new generation of leaders who lead the American people, build people's sovereignty, forge ahead and serve the people wholeheartedly. The extensive use of physical processes in transitive systems makes it stated that American citizens should have exciting, fulfilling careers. The high frequency of relationship processes highlights that every task, no matter how hard, how challenging, how dangerous, should be dignified and noble; the use of modals, especially medium modals, makes the political prospect conveyed by them more acceptable to the public. The frequent use of "we, our" in personal pronouns has brought Trump closer to his audience and won him popular support. Critical discourse analysis excavates hidden information, reveals the relationship between language power and ideology, and shows how language becomes the tool of ideology, which provides a new perspective for the interpretation of political discourse.

\section{APPENDIX}

My fellow Americans, this week, our nation was shocked and horrified when a gunman opened fire on a Member of Congress. Five people were wounded in the assault, including a member of House Leadership - my good friend, Steve Scalise. Steve is beloved across Washington, he embodies everything public service is about, he's dedicated to his constituents, devoted to his values, and deeply committed to his country.

I visited Steve, his wife, and his family in the hospital as he continues to fight for his recovery. 435 Members of Congress, and 300 million Americans, are pulling for him, praying for him, and pledging to him our full and total support. We continue to hold all of those wounded and fighting for recovery in our hearts and prayers, including Matt Mika, who was also badly wounded. In that terrible crime, we also witnessed the incredible heroism of Capitol Police.

Special Agent Crystal Griner - who I also had the honor of meeting during my visit to the Hospital - raced into gunfire, along with Special Agent David Bailey. They saved the lives of our Members of Congress and prevented that dark day from becoming a tragedy beyond imagination. They, like so many other courageous police officers, represent the very best of us. We salute them, and we also salute members of Alexandria Police, Fire and Rescue. Though we have our differences, what unites us is so much stronger: our love of country, our devotion to its people.

Now more than ever, these values must guide us - and bring us closer together. Let us always remember that our job is to serve and represent the whole American People - and that we are all children of the same God. This week, my Administration continues our focus on providing economic opportunity for all. On Thursday, I signed an Executive Order to launch a groundbreaking new Apprenticeship Initiative that help young Americans learn the skills they need to find a rewarding career, earn a great living, and support themselves and their families. We are celebrating the dignity of work and the greatness of the American Worker.

American citizens have worked every job, every occupation, no matter what it might be - no matter how grueling, how challenging, or even how dangerous. They wash the windows on our tallest skyscrapers; they create works of art from burning fire and molten steel; they mine the earth and dive the ocean depths to bring energy into our cities and towns; they care for the sick, the elderly, and the wounded; and they lay the bricks, mortar, rebar, and concrete that give us places to live, to work, and to thrive.

Today, this is the message I want every young American to hear: there is dignity in every honest job, and there is nobility in every honest worker. Our Apprenticeship Initiative will make it dramatically easier for employers, industry groups and unions to create exciting new apprenticeship programs that place students into high-paying careers. Instead of being racked with crushing student debt, those who participate will earn while they learn - think of that: earn while they learn. Under our plan, young Americans will have a pathway to exciting and fulfilling careers. 
They will become brilliant technicians who revitalize American manufacturing.

They will become welders who forge from fire, amazing works of iron and steel and art.

And they will become entrepreneurs who revolutionize entire industries.

And these striving American citizens, including millions of talented young American women with tremendous potential, will become the programmers who change the world with the next great technological advance. Every American deserves a path to a great job that they truly love. That begins with the right education - one that gives students the foundation for a lifetime of success. Every day, as your President, I will be committed to this goal.

Thank you, God bless you, and God bless America.

\section{REFERENCES}

[1] Ding Jianxin \& Liao Yiqing. (2011). Critical Linguistics. Beijing: Foreign Language Teaching and Research Press.

[2] Fairclough, N. (1995). Critical Discourse Analysis. London: Longman.

[3] Fowler, R. (1979). Language and Control. London: Routledge.

[4] Halliday, M. A. K. (1994). An Introduction to Functional Grammar. Beijing: Foreign Language Teaching and Research Press.

[5] Hodge, R. \& G. Kress. (1979). Language as Ideology. London: Routledge \& Kegan Paul.

[6] Hu Zhuanglin. (2002). A Course in Linguistics. Beijing: Peking University Press.

[7] Hu Zhuanglin \& Zhu Yongsheng. (2008). Introduction to systemic-Functional Grammar. Beijing: Peking University Press.

[8] Ji Weining \& Xin Bin. (2009). Fairclough's Theory of Critical Discourse Analysis. Foreign Languages, 6, 21-25.

[9] Li Yuanshu \& Zou Kunshan. (2003). Speech Science. Wuhan: Huazhong University of Science and Technology press.

[10] Li jie \& Zhong Yongping. (2002). Modal System and Function of English. Foreign language teaching, 1, 9-11.

[11] Paltridge, B. (2012). Discourse Analysis an Introduction (2nd Ed). London: Bloomsbury.

[12] Tian Hailong. (2009). Discourse Research: Categories, Perspectives, Methods. Shanghai: Shanghai Foreign Language Education Press.

[13] Xin Bin. (2002). Critical Discourse Analysis Methodology. Foreign Languages, 6, 34-41.

[14] Xin Bin. (2005). Critical Linguistics: Theory and Application. Shanghai: Shanghai Foreign Language Education Press.

[15] Xin Bin \& Gao Xiaoli. (2013). Critical Discourse Analysis: Objectives, Methods and Dynamics. Foreign Languages and Foreign Language Teaching, 4, 1-5.

[16] Zeng Yaping. (2009). Interpretation of Obama's Presidential Victory Speech from the Perspective of CDA. Foreign Languages and Foreign Language Teaching, 2, 19-21.

[17] Zhang Lei. (2005). Interpreting Bush's Speech with Critical Discourse Analysis. Journal of Xi 'an International Studies University, 1, 23-25.

[18] Zhang Delu. Miao Xingwei \& Li Xuening. (2005). Functional Linguistics and Foreign Language Teaching. Beijing: Foreign Language Teaching and Research Press.

Lirong Tian was born in Chongqing, China in 1989. Now, she is a postgraduate student in linguistics in Chongqing Normal University, China. Her research interests include foreign language teaching and cognitive linguistics. 